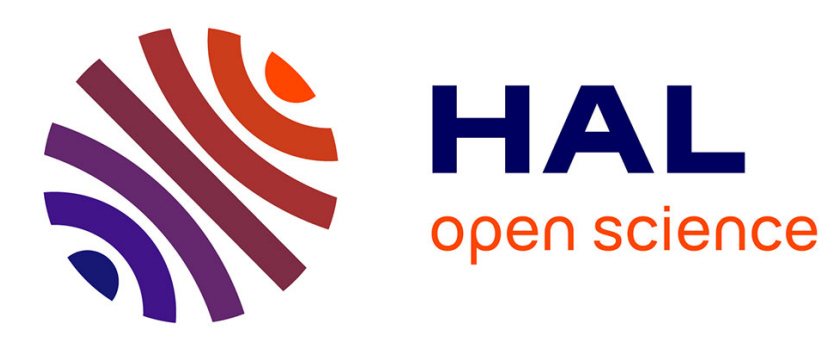

\title{
The pollination potential of free-foraging bumblebee (Bombus spp.) males (Hymenoptera: Apidae)
}

Stephan Wolf, Robin Moritz

\section{To cite this version:}

Stephan Wolf, Robin Moritz. The pollination potential of free-foraging bumblebee (Bombus spp.) males (Hymenoptera: Apidae). Apidologie, 2014, 45 (4), pp.440-450. 10.1007/s13592-013-0259-9 . hal-01234738

\section{HAL Id: hal-01234738 \\ https://hal.science/hal-01234738}

Submitted on 27 Nov 2015

HAL is a multi-disciplinary open access archive for the deposit and dissemination of scientific research documents, whether they are published or not. The documents may come from teaching and research institutions in France or abroad, or from public or private research centers.
L'archive ouverte pluridisciplinaire HAL, est destinée au dépôt et à la diffusion de documents scientifiques de niveau recherche, publiés ou non, émanant des établissements d'enseignement et de recherche français ou étrangers, des laboratoires publics ou privés. 


\title{
The pollination potential of free-foraging bumblebee (Bombus spp.) males (Hymenoptera: Apidae)
}

\author{
Stephan Wolf ${ }^{1,2, *}$, Robin F. A. Moritz ${ }^{1,3}$ \\ ${ }^{1}$ Institut für Biologie/Zoologie, Martin-Luther-Universität Halle-Wittenberg, Halle a.d. Saale, Germany \\ ${ }^{2}$ Department of Agro-Ecology, Rothamsted Research, Harpenden, UK \\ ${ }^{3}$ Department of Zoology and Entomology, University of Pretoria, Pretoria, South Africa
}

Received 2 July 2013 - Revised 15 November 2013 - Accepted 26 November 2013

\begin{abstract}
Bumblebee workers are efficient pollinators. However, despite their flower visits and less intense grooming the role of males as pollen vectors is largely unexplored. We compared the quantity and diversity of pollen on the bodies (pollination-active pollen) of free-foraging workers and males of two bumblebee species (Bombus lapidarius and Bombus terrestris) to assess their pollination potential. In both species, males exhibit worker-like flower constancy, but differ significantly from workers in the predominantly collected pollen types. Mean pollen loads of approximately 10,000 grains/individual suggest that males can contribute to the colony pollination service. Bumblebee males add to the diversity of pollinators, associated to increased crop pollination and facilitate pollen flow in specific ways, worthwhile further investigation.
\end{abstract}

\section{bumblebee males / pollen loads / colony pollination service / flower constancy}

\section{INTRODUCTION}

Pollination of flowering plants by animal pollinators is an essential ecosystem function (Midgley and Bond 1991; Sargent and Ackerly 2008). Among the diverse suite of flowervisiting insects, bumblebees (Bombus spp.) are among the most efficient pollinators in the temperate and cold climate zones (Bingham and Orthner 1998; Goulson, 2003). Numerous studies on pollination efficiency and pollen dispersal illustrate the outstanding pollination potential of bumblebee workers (Campbell 1991; Kwak, et al. 1998), which well exceeds

Corresponding author: S. Wolf, s.wolf@qmul.ac.uk Manuscript editor: James Nieh

*Current address: School of Biological and Chemical Sciences, Queen Mary University of London, Mile End Campus, E1 4NS, London, UK that of honeybees (Apis mellifera) for many wild and managed plants (Westerkamp 1991). In contrast to the vast number of studies conducted on foraging behaviour of bumblebee workers (Heinrich 1976; Pyke 1978; Cartar and Dill 1990; Chittka, et al. 1997; Goulson, et al. 1997; Osborne, et al. 2008; Wolf and Moritz 2008), male bumblebees have been addressed only rarely in this context. Although the patrolling behaviour of bumblebee males was already recognized by Darwin (1886), studies on males focus almost exclusively on reproductive physiology (Alcock, et al. 1978; Eickwort and Ginsberg 1980; Duvoisin, et al. 1999) with few exceptions addressing foraging and flower visitation (Ranta and Lundberg 1981; Bertsch 1984; Ostervik, et al. 2010). Indeed, apart from recent work on two species of orchid (Ophrys normanii and Ophrys chestermanii), which are pollinated by males of the cuckoo-bumblebee Bombus (Psithyrus) vestalis (Gögler, et al. 
2009) and insightful lab-experiments on male Bombus impatiens (Ostervik, et al. 2010), we are not aware of any report on the potential impact of free-flying bumblebee males on pollination.

In contrast to workers, males do not return to the nest. While establishing and monitoring their patrol routes to attract receptive queens (Darwin 1886; Haas 1949; Svensson 1979; Alcock, et al. 1978; Eickwort and Ginsberg 1980; Bergman and Bergström 1996; Ayasse, et al. 2001), the males also need to visit flowers to fuel this energetically expensive behaviour (Svensson 1979). Pollen deposited on the males' body while foraging on a flower may be transferred to the next flower visited on the foraging bout. Ostervik, et al. (2010) showed that the prolonged flower handling times of $B$. impatiens males under laboratory conditions increased pollen transfer. The same study also found more frequent between-patch flights of males potentially increased out-crossing (Ostervik, et al. 2010).

Additionally, the population level male flight range has been estimated to exceed the flight range of foraging workers by a factor of at least 1.6 (B. terrestris and Bombus lapidarius; Wolf, et al. 2012) and up to as much as 17-fold ( $B$. terrestris, Kraus, et al. 2009). Although this increase may not directly reflect flower-toflower movement, the much higher lifetime dispersal rates are still likely to increase the spatial scale of male-mediated pollen flow compared to that of the colony-based workers.

Foraging workers frequently groom their body to collect pollen in their pollen baskets on the tibia (i.e. corbiculae; Thorp 1979). This pollen is lost for pollination (Free and Williams 1972; Thomson 1986) and causes a considerable discrepancy between workers foraging efficiency and their pollination service (Westerkamp 1991). Males, in contrast, lack corbiculae and grooming is less intense (e.g. Thomson and Plowright 1980), therefore, they are often "pollen powdered" after flower visits potentially promoting pollen flow.

Pollen dispersal, however, does not per se imply efficient pollination. Whenever pollen is not transferred to the flower of a conspecific plant, pollination has failed. Foraging workers are preferably attracted to one plant species ("majoring") and display a high level of flower constancy (Heinrich 1979a; Waser 1986; Gegear and Laverty 2005; Raine and Chittka 2005). This short-term fidelity to particular plant species forms the basis of the pollination efficiency of bumblebee workers (e.g. Laloi, et al. 1999, Goulson 2003) and increases the efficiency of foraging and colony provisioning. Bumblebee males, however, do not forage for the colony but exclusively for themselves to obtain energy for mating flights and mating (Svensson 1979; Goulson 2003). The motivation of flower visits may therefore be very different between males and workers.

Here we assess the quantity and quality of pollen loads of bumblebee males in comparison to workers in order to estimate the pollen flow and flower constancy as measures for pollination potential of males of two common bumblebee species (B. lapidarius and B. terrestris) in relation to their workers. Given the importance of (long-distance) pollen flow for insectpollinated plants in especially fragmented ecosystems (Sork, et al. 1999; Couvet 2002; Ghazoul 2005; Aguilar, et al. 2008), it is important to investigate the role of bumblebee males as potential pollinators (Thomson and Plowright 1980; Ackerman, et al. 1982).

\section{MATERIALS AND METHODS}

\subsection{Bee sampling}

Workers and males of $B$. terrestris and $B$. lapidarius were sampled from June 18th to July 27th, 2007 in the flower-rich urban park "Heide-Süd" in Halle/Saale, Germany (51²9'30 N; 11 ${ }^{\circ} 56^{\prime} 10$ W). Bees were randomly collected from flowers using an insect net. Flower visitation was the only criterion for sampling disregarding potential foraging specializations of individual bees (i.e. pollen or nectar foragers) (Hagbery and Nieh 2012).

After initial species identification in the field, bees were sacrificed with ethyl acetate and the two hind legs were clipped. Both legs and the remaining bodies (hereafter referred as "body") were stored 
separately in ethanol (70 \%) in two individual Eppendorf tubes until pollen analysis.

All individuals were again microscopically checked for species identity and sex using the identification key of Mauss (1994). Using a calliper, we also measured the length of the extended proboscis (including glossa) of a randomly chosen sub-sample from each sex and species $\left(n=26 ; n_{\text {total }}=\right.$ 104), which is known to correlate with the corolla length of the visited flowers and can cause specific foraging patterns (Inouye 1980).

\subsection{Pollen samples}

Pollen loads of the bodies (pollination-active pollen) were quantified and qualified from homogenous pollen solutions. Pollen grains were washed off the bodies through vortexing in $3 \mathrm{~mL}$ HPLC water-SDS solution $(5 \%)$. Pollen grains already washed off in the ethanol storage solution were pelleted by centrifugation $(15,000 \mathrm{rpm}, 15 \mathrm{~min})$ and added to the pollen suspension to avoid pollen loss. All pollen suspensions were subsequently centrifuged $(15,000 \mathrm{rpm}, 15 \mathrm{~min})$ and re-suspended in $100 \mu \mathrm{L}$ HPLC water-SDS solution to obtain a standardized concentration for pollen counts. Though pollen grains occasionally may be damaged from the centrifugation, deformed or fragmented pollen grains were rare throughout all samples.

For high pollen concentrations the pollen solutions were further diluted until reliable pollen counts and type assignments could be done. Pollen loads per bee were microscopically quantified using a FuchsRosenthal counting chamber at $\times 100$ magnification and correcting for the used dilution.

Since we could not identify the individual plant species for every pollen grain with certainty, each grain was assigned to clearly distinguishable categories ("pollen types") based on size, shape and structure. New categories were established for any so far undetected pollen type, such that most pollen grains per sample were assigned to a type. Deformed pollen grains or grain fragments that could not be reliably assigned to any category were excluded from any further analysis. Using Von der Ohe and Von der Ohe (2003) some pollen types could be roughly matched to the typical pollen appearance of some plants flowering in the area: A: Echium vulgare, B: Rubus spp./Rosa spp., D: Trifolium repens; E:
Carduus spp./Cirsium spp., F: Trifolium pratense, $\mathrm{H}$ : Lotus corniculatus and K: Leontodon spp. Other (infrequent) pollen types could not be associated to a forage resource.

\subsection{Data analysis and statistics}

The composition of an individual bees' pollen load is not only determined by the bees' behaviour and/or morphological characteristics but also by the availability of pollen in the foraging area. Measuring the total amount of pollen available for pollination in a given area is difficult at best. However, the total amount of pollen found on the bodies of bees foraging in a specific area may provide a useful proxy representing those flowers actually visited by bees. It may also reflect the quantity of pollen that is typically deposited during a flower visit on a bee's body and remain there available for pollination during subsequent flower visits.

We, therefore, processed the recorded pollen loads of each species and sex (i.e. four different groups: $B$. lapidarius males, $B$. lapidarius workers, $B$. terrestris males and $B$. terrestris workers) in two different ways. First we used the overall sum of pollen grains of each pollen type within each of the four groups to subsequently ranked these cumulative pollen numbers descending from the most to least frequent pollen type. We used this ranked pollen spectrum as a proxy for the overall pollen availability in the landscape (hereafter referred to as "expected").

Secondly, we individually ranked the pollen types found on each bee, again descending from the most to least frequent pollen types on that specific bee. After the individual ranking we calculated the mean and total number of pollen grains in each rank (hereafter referred to as "observed"). As the most frequently present pollen type can vary from bee to bee, rank sums and means per group are typically composed of a mixture of several pollen types. The pollen type composition of the first rank was used to compare the foraging preferences of males and workers, if any.

In case of non-preferential foraging, i.e. bees visiting flowers at random, we expect the individual pollen load composition (observed) to follow closely the pollen composition of the area (expected). Here the most frequently available pollen type should 
consistently dominate the individual pollen loads. Alternatively, preferential foraging is expected to result in marked differences between individual pollen loads and the pollen distribution in the landscape. Also pollen load compositions between individual bees are expected to vary more or less widely rather than uniformly following the expected distribution. To test for preferential flower visitation we, therefore, compared the expected distribution of pollen types to the observed cumulative pollen loads in each group.

All statistical analyses were performed using the statistical software GenStAT for Windows (14th Edition). We used a linear mixed model (LMM) fitted by restricted maximum likelihood (REML) suited for highly unbalanced datasets. For comparisons of the pollen loads among species and sexes we used a crossed fixed model (species $\times$ sex $\times$ pollen type) and a nested random model (bee ID). We also used REML to test whether the individual ranked pollen distribution is reflected by the ranked overall distribution of pollen types using species $\times$ sex $\times$ ranking mode (i.e. ranked expected vs. ranked observed) as fixed model. Where necessary, parameters were transformed using $\log _{10}(x+1)$ to achieve variance homogeneity and normal distribution.

\section{RESULTS}

We analysed pollen loads on the body surface (pollination active pollen) of males ( $n_{3 \text { lap }}=40$ and $\left.n_{\delta \text { terr }}=53\right)$ and workers ( $n_{\text {○lap }}=46$ and $n_{\text {oterr }}=48$ ) of $B$. lapidarius ("lap") and $B$. terrestris ("terr"). Overall ten pollen types could be clearly distinguished with six (B. lapidarius) and eight pollen types (B. terrestris) present on more than $10 \%$ of the individuals (pollen type frequencies per bee ranged $0-95 \%(\precsim) / 0$ $100 \%(+$ ) and 0-92\% (ð)/0-98\% (中) in $B$. lapidarius and B. terrestris, respectively).

\subsection{Pollen quantity}

The estimated total numbers of pollen grains on the individual bees' bodies significantly varied among pollen types (PT), species (S) and between sexes $(\mathrm{SX})\left(F^{\mathrm{PT}}{ }_{9,1,169.5}=285.23\right.$, $p<0.001 ; \quad F_{1,181.3}^{\mathrm{S}}=27.35, \quad p<0.001 ;$ $\left.F_{1,247.3}^{\mathrm{SX}}=285.2, P<0.001\right)$. Overall workers of both species carried significantly more pollen grains on their body surface than the males did (B. lapidarius: pollen quantity $(\mathrm{QN})_{+1 \mathrm{lap}}=$ $40,784.78 \pm 3,809.96$ (SE) vs. $\mathrm{QN}_{31 \mathrm{ap}}=$ $10,335.00 \pm 1,561.10$ (SE); B. terrestris: $\mathrm{QN}_{\text {terr }}=57,900.00 \pm 8,841.71$ (SE) vs. $\mathrm{QN}_{\text {terr }}=13,049.06 \pm 2,888.18$ (SE) $\left(F^{\mathrm{S} \mathrm{SX}_{1,246.2}}=4.01, P<0.05\right)$.

\subsection{Pollen load composition and flower constancy}

In both bumblebee species ranking of the individual pollen loads revealed that one pollen type per individual dominated ("major") the total pollen load composition within each sex (major $_{\delta \text { lap }}=67.7 \% \pm 0.02$ (SE) vs. major $_{\odot \text { lap }}=$ $75.3 \% \pm 0.02(\mathrm{SE}) ;$ major $_{\bar{\delta} \text { terr }}=62.3 \% \pm 0.02$ (SE) vs. major $_{\text {terr }}=72.7 \% \pm 0.03 \quad(\mathrm{SE})$ ) (Figure 1a, b).

Comparing the ranked pollen distribution found on the bees (observed, O) with the approximated pollen spectrum provided by the landscape (expected, E), we found that the pollen counts in the "majoring"-rank (sum of observed rank 1) were significantly higher as compared to the most frequent pollen type in the landscape (sum of expected rank 1; $\left.F^{\mathrm{O}-\mathrm{E}}{ }_{1,108.0}=5.75, P<0.018\right)$. Likewise, other pollen types were less frequently found than expected from overall pollen availability (Figure 2). This effect was consistent across both species and sex $\left(F_{1,108.0}^{\mathrm{S}}=1.87, \quad P=0.18 ; \quad F_{2,108.0}^{\mathrm{SX}}=1.50\right.$, $\left.P=0.23 ; F^{\mathrm{S} \mathrm{SX}^{*} \mathrm{O}-\mathrm{E}}{ }_{2,108.0}=0.09, P=0.91\right)$.

Analyzing the composition of the "majoring"-rank we found significant differences in the majored pollen types between workers and males $\left(F^{\mathrm{SX} * \mathrm{PT}}{ }_{91,669.5}=10.92\right.$, $P<0.001$; Figure 3a, b). Workers of $B$. lapidarius predominantly majored pollen type A $(60.9 \%$ of all individuals) which was only majored by $7.5 \%$ of the males. The males almost equally majored on pollen type B and E (42.5 and $40 \%$ of all individuals), which were only majored by $6.5 \%$ (B) and $19.6 \%$ (E) of the workers. Similarly, workers and males in $B$. terrestris 

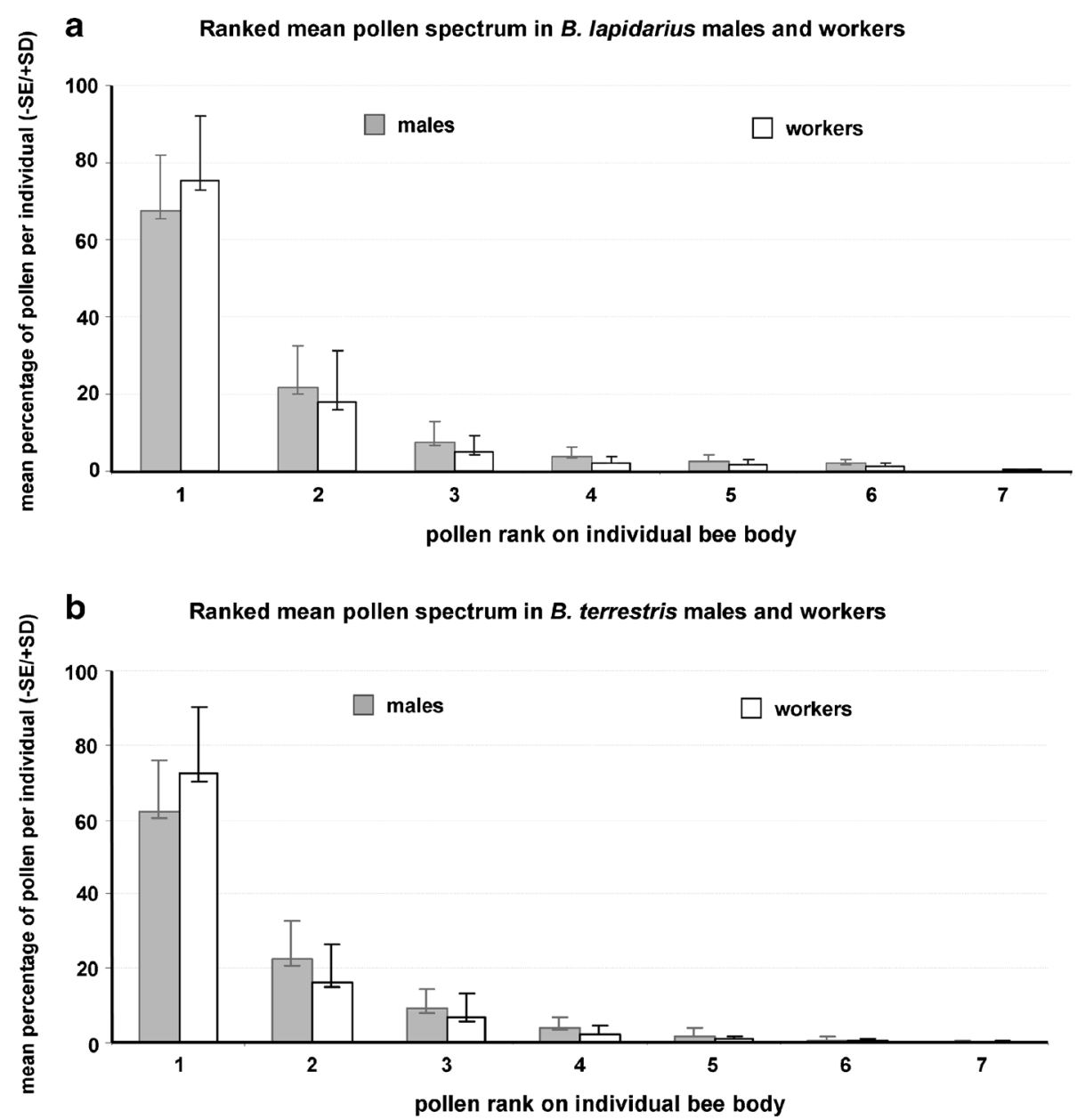

Figure 1. Means of the pollen ranks on the bodies of individual bees (- standard error/+ standard deviation) in males and workers of a $B$. lapidarius and $\mathbf{b} B$. terrestris. Pollen categories were ranked according to their individual frequency. In both sexes one pollen type per individual was overrepresented ( $>60 \%)$ in comparison to the other types found on the body typical for "majoring" and "minoring".

show a diametrically opposed majoring frequency on pollen types $\mathrm{A}$ and $\mathrm{E}$, the two most frequently majored pollen types for both sexes (majorA $+\mathrm{E}_{\text {oterr }}=91.7 \%$; major $\mathrm{A}+\mathrm{E}_{\widehat{\delta} \text { terr }}=$ $88.7 \%$ ). Workers mostly majored on pollen type A (64.6\%; males, $15.1 \%$ ), whereas $73.6 \%$ of the males majored on pollen type $\mathrm{E}$ (workers, $27.1 \%$; Figure 3a, b).

The proboscis length (PL) were in both species were significantly longer in males than in workers (B. lapidarius: $\mathrm{PL}_{\widehat{\delta}}=5.2 \mathrm{~mm} \pm 0.07$ $(\mathrm{SE})$ vs. $\mathrm{PL}_{\odot}=4.7 \mathrm{~mm} \pm 0.07(\mathrm{SE}) ;$ B. terrestris: $\mathrm{PL}_{\widehat{O}}=5.9 \mathrm{~mm} \pm 0.07$ (SE) vs. $\mathrm{PL}_{\phi}=5.2 \mathrm{~mm} \pm$
$0.12(\mathrm{SE}) ; F^{\mathrm{S}}{ }_{1,100.0}=48.68, P=0.18 ; F^{\mathrm{SX}}{ }_{1,100.0}=$ 44.41, $P<0.001)$. B. terrestris workers had similar tongue lengths as $B$. lapidarius males $\left(F^{\mathrm{S*SX}}{ }_{1,100.0}=0.58, P<0.45\right)$.

\section{DISCUSSION}

Our results provide the one of the first indications that bumblebee males may well be important pollinators and considerably contribute quantitatively and qualitatively to the colony pollination service. The efficiency of beemediated pollen transfer is independent of the 

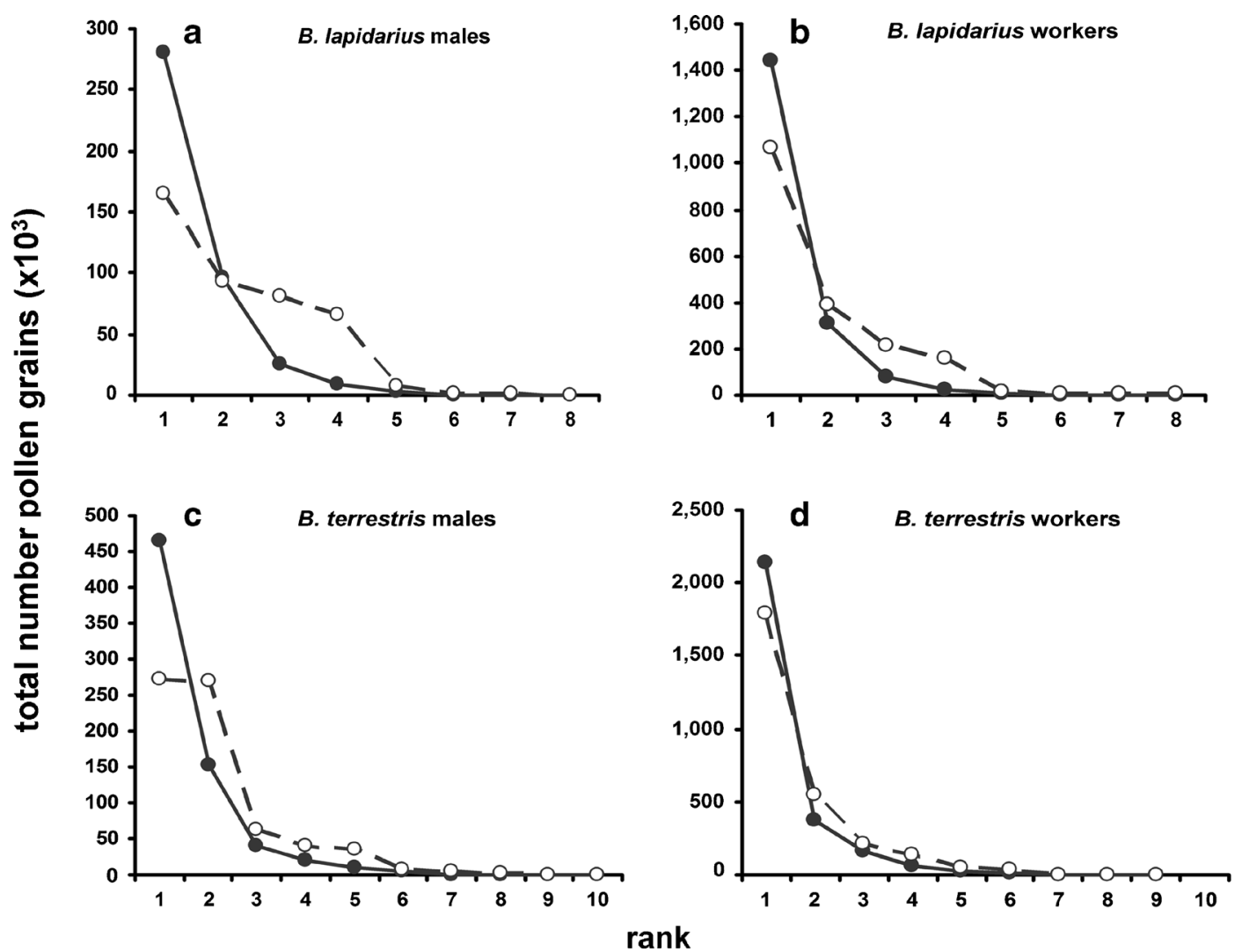

Figure 2. Ranked observed (filled circles) versus ranked expected (open circles) total numbers of pollen grains per species and sex. In all cases rank 1 of the observed pollen counts ("majored" pollen type per bee) were significantly higher than the most frequently available pollen type in the landscape (expected), whereas individual pollen counts for the lower ranks were consistently underrepresented with respect to potentially available pollen. This indicates preferential flower choice (majoring) independent of pollen availability in the foraging area in both workers and males.

bees foraging specialization (Heinrich 1976). We therefore indiscriminately sampled workers independent of their foraging specialization (nectar, pollen and both; Hagbery and Nieh 2012) as well as flower-visiting males allowing for a comprehensive assessment of pollen flow through bumblebees.

We could show that bumblebee males carry substantial numbers of pollen on their body surface, potentially available for pollination. In contrast to our initial hypothesis, however, males carried less pollen on their bodies than workers did. This is counterintuitive given their weak grooming behaviour in comparison to foragers but might be explained by a lower frequency of flower visits compared to workers.
Workers visit flowers to forage pollen and nectar for the demands in the colony, hence collecting a multiple of their own energy demands (Heinrich 1979b). Males, in contrast, visit flowers only for their own energy demands and typically spend most of the day patrolling (Svensson 1979; Goulson 2003). They preferentially forage early in the morning and late in the afternoon (Svensson 1979; Alcock, et al. 1978; Eickwort and Ginsberg 1980), which may result in fewer flower visits per day than for foragers. Nevertheless, a mean of over 10,000 pollen grains per individual male should be sufficient to facilitate pollination in most plants. Carré, et al. (1994) examined pollen numbers on head and thorax of $B$. terrestris workers finding 
Majored pollen type composition in males $(\square)$ and workers ( $\square$ )
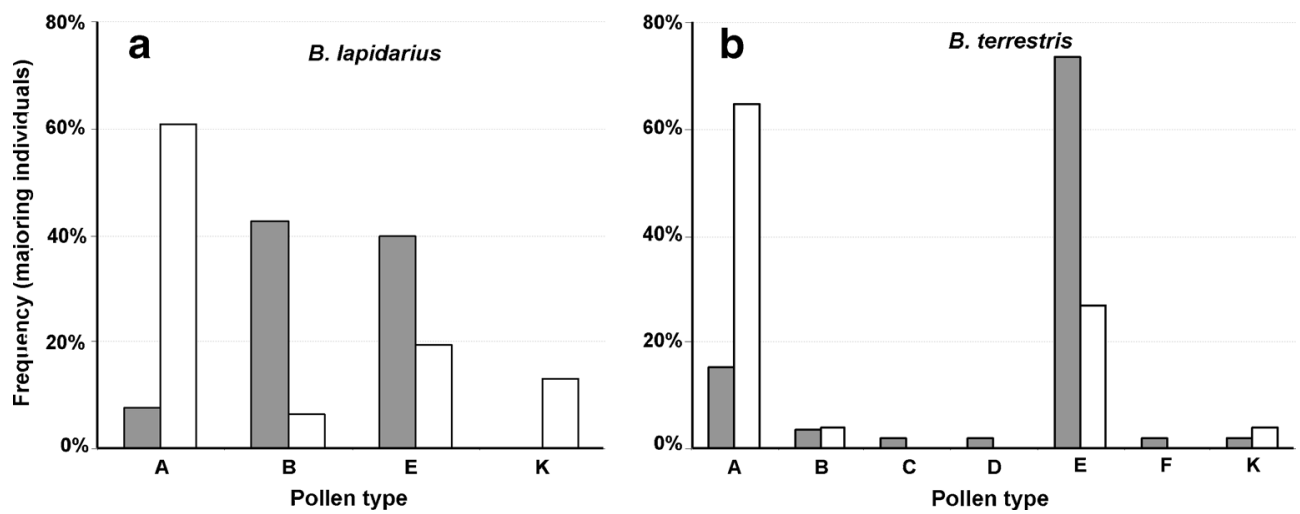

Figure 3. Pollen type composition of the 1. rank (most abundant pollen per individual) per sex in a $B$. lapidarius and $\mathbf{b}$ B. terrestris. There is a highly significant difference in pollen type representation between sexes in both species indicating that males may complement the pollination potential of workers broadening a colonies overall pollination service.

only $1,620 \pm 300$ to $6,300 \pm 400$ grains after ten visits of Vicia faba flowers. In other pollinatorplant systems even lower numbers of loose pollen grains per pollinator seem to suffice for pollination (Bombus-Pontederia, 28.5-74.5; Apis-Pontederia, 14.0-49.1; MelissodesPontederia; 30.4-52.0 (Wolfe and Barrett 1989); specialist bees-Clarkia, 335 \pm 73 ; generalist bees-Clarkia, 81 \pm 29 (Moeller 2005)).

Our results strongly indicate that males of both species did not visit flowers at random but displayed the typical "majoring" and "minoring" described for workers (e.g. Heinrich 1979a). Though based on pollen types, which may not necessarily represent a flower species, our approach provided sufficient resolution to clearly demonstrate the well-known flower constancy in workers. From this, methodological constraints artificially causing the demonstrated effects in males but not in workers are highly unlikely. Also, our results are in line with reports on selective, female-like foraging behaviour of male orchid bees (Ackerman, et al. 1982).

Finding preferential foraging in both workers and males is not surprising, since the visitation of rewarding flowers should be highly adaptive for both sexes as it optimizes the net energy gain per time unit (Bertsch 1984; Real 1991;
Waddington 2001), reduces the risks of predation (Cartar 1991; Dukas 2001; Abbott 2006) and infection (Durrer and Schmid-Hempel 1994).

The ability to learn and memorize rewardlinked floral traits (e.g. Menzel 2001; Raine and Chittka 2007; Raine and Chittka 2008) and its efficient exploitation (e.g. Lihoreau, et al. 2011; 2012) has been impressively demonstrated in bumblebee workers (Laloi, et al. 1999). Although the cognitive abilities of bumblebee males remain to be studied our results suggest that the cognitive mechanisms driving flower choice may be very similar in males and workers. Indeed, the learning capacity of honeybee (A. mellifera) drones (Benatar, et al. 1995) was shown to be similar to that of workers despite drones, being fed by workers in the colony, are not foraging on flowers.

Alcock, et al. (1978) pointed out, males of several Apoidea species are attracted by flowers that are also highly attractive to females (including gynes) and visits to particular flowers may enhance their chances to encounter a mate by visiting these flowers. However, with an elaborate and costly pre-mating behaviour in form of patrolling (Alcock, et al. 1978; Eickwort and Ginsberg 1980) it is unlikely that flowers are chosen to increase queen encounter rates. 
A more likely factor driving the difference in the pollen spectra of males and workers may be the differences in nutritional demands. Whereas workers are attracted by flowers providing either nectar or pollen or both (e.g. Waddington 2001), it would be adaptive for males to only prefer rich nectar providing flowers, since they do not feed on pollen (Ranta and Lundberg 1981). Though flower rewards were not measured, this difference may well be the driving force behind our findings, where males obviously preferred different flowers than workers as inferred from the pollen spectra differing significantly between both sexes.

Proboscis lengths differences have repeatedly shown to affect the exploitation of tube-shaped flowers (i.e. Red Clover) both between bumblebee species (e.g. Inouye 1980) and even within a colony (tongue length correlating with worker body size: Harder 1985; size-specific foraging performance: Spaethe and Weidenmüller 2002). In our dataset proboscis length of $B$. lapidarius males and $B$. terrestris workers were very similar. If tongue-length alone would determine flower choice, one should expect overlapping pollen compositions of these two groups. This is not what we found. In an area rich in easily exploited flowers, proboscis length is likely to be only of minor importance.

The pollen dispersal by male bumblebees might resemble that of other freely dispersing pollinators like butterflies, moth or hoverflies. Like adult bumblebee males, they lead a solitary life and mostly visit flowers for nectar and consume no or only little pollen (Kevan and Baker 1983). Detailed information about pollen flow through non-bee pollinators is limited (Courtney, et al. 1982; Nilsson, et al. 1987; Chase, et al. 1996) but the importance of these pollinators has repeatedly been emphasized (Weiss, 2001; Biesmeijer, et al. 2006, Garibaldi, et al. 2013). In fact, Herrera (1987) found pollinator effectiveness of some Lepidopteran pollinators higher than that of honeybees and surpassed only by a number of solitary bee species. Butterflies also facilitated more outcrossing on Lavandula latifolia as compared to bee pollinators due to longer inter-flower flights (Herrera 1987). Some studies also emphasize the potential importance of butterflies and moth for long-distance pollination, especially if pollen remains on the insect over a long period of time (Courtney, et al. 1982; Chase, et al. 1996). Further studies assessing the time pollen remains available for pollination on bumblebee males' bodies over time and the inter-floral movement patterns of foraging bumblebee males during this time will be able to conclusively address the spatial scale and effectiveness of pollen dispersal through male bumblebees.

In conclusion, our data suggests that bumblebee males are behaviourally and morphologically well equipped to substantially contribute to pollination. In light of the extended population-level flight ranges and different flower choices compared to workers, they may well complement the pollination activities of the workers and hence expand the pollination service of the bumblebee colony as a whole. An increase in crop pollination efficiency with increased wild bee diversity as compared to managed pollinators alone (Klein, et al. 2003; Garibaldi, et al. 2013) strikingly illustrates the importance of a (behaviourally) diverse pollinator assemblage for ecosystem function. Bumblebee males certainly add to the diversity of flower visitors and contribute in specific ways to insect-mediated pollen flow.

Given these promising findings and the numerous still open questions it is clearly most timely to invest more research on the role of male bees as pollinators and sex-specific aspects of pollination efficiency in general.

\section{ACKNOWLEDGMENTS}

We like to thank Susan Brich, Stephanie Gerschke, Diana Oelschlägel, Olga Skljar and Maria Tauber for valuable help during field work. Thanks to F. B. Kraus and two anonymous reviewers for constructive comments that clearly improved the manuscript. This study was funded by the EU-Project ALARM (Assessing LArge scale Risks for biodiversity with tested Methods; Pollinator Module, EU Contract No.: 506675). Rothamsted Research is a national institute of bioscience strategically funded by the UK Biotechnology and Biological Sciences Research Council (BBSRC). 
Le potentiel de pollinisation des bourdons mâles, Bombus spp. (Hymenoptera: Apidae) butinant pour eux-mêmes

\section{Bourdon / mâle / charge pollinique / rôle pollinisateur d'une colonie/fidélité florale}

\section{Das Bestäubungspotential von freifliegenden Hummelmännchen (Bombus spp., Hymenoptera: Apidae)}

\section{Hummelmännchen / Pollenladungen / Bestäubungsservice / Blütenstetigkeit}

\section{REFERENCES}

Abbott, K.R. (2006) Bumblebees avoid flowers containing evidence of past predation events. Can. J. Zool. 84, 1240-1247

Ackerman, J.D., Mesler, M.R., Lu, K.L., Montalvo, A.M. (1982) Food-foraging behaviour of male Euglossini (Hymenoptera: Apidae) - vagabonds or trap-liners? Biotropica 14(4), 241-248

Aguilar, R., Quesada, M., Ashworth, L., HerreriasDiego, Y., Lobo, J. (2008) Genetic consequences of habitat fragmentation in plant populations: susceptible signals in plant traits and methodological approaches. Mol. Ecol. 17, 5177-5188

Alcock, J., Barrows, E.M., Gordh, G., Hubbard, L.J., Kirkendall, L., Pyle, D.W., Ponder, T.L., Zalom, F.G. (1978) The ecology and evolution of male reproductive behaviour in the bees and wasps. Zool. J. Linn. Soc. 64, 293-326

Ayasse, M., Paxton, R.J., Tengö, J. (2001) Mating behaviour and chemical communication in the order Hymenoptera. Annu. Rev. Entomol. 46, 31-78

Benatar, S.T., Cobey, S., Smith, B.H. (1995) Selection on a haploid genotype for discrimination learning performance: Correlation between drone honeybees (Apis mellifera) and their worker progeny (Hymenoptera: Apidae). J. Insect Behav. 8(5), 637-652

Bergman, R., Bergström, G. (1996) Scent marking, scent origin, and species specificity in male premating behaviour of two Scandinavian bumblebees. J. Chem. Ecol. 23(5), 1235-1251

Bertsch, A. (1984) Foraging in male bumblebees (Bombus lucorum L.): maximizing energy or minimizing water load? Oecologia 62, 325-336

Biesmeijer, J.C., Roberts, S.P.M., Reemer, M., Ohlemüller, R., Edwards, M., et al. (2006) Parallel declines in pollinators and insectpollinated plants in Britain and the Netherlands. Science 313, 351-354

Bingham, R.A., Orthner, A.R. (1998) Efficient pollination of alpine plants. Nature 391, 238-239
Campbell, D.R. (1991) Comparing pollen dispersal and gene flow in a natural population. Evolution 45(8), 1965-1968

Carré, S., Badenhausser, I., Taséi, J.N., Le Guen, J., Mesquida, J. (1994) Pollen deposition by Bombus terrestris L. between male-fertile and male-sterile plants in Vicia faba L. Apidologie 25, 338-349

Cartar, R.V. (1991) A test of risk-sensitive foraging in wild bumblebees. Ecology 72(3), 888-895

Cartar, R.V., Dill, L.M. (1990) Colony energy requirements affect the foraging currency of bumblebees. Behav. Ecol. Sociobiol. 27, 377-383

Chase, M.R., Moller, C., Kesseli, R., Bawa, K.S. (1996) Distant gene-flow in tropical trees. Nature 383, 398-399

Chittka, L., Gumbert, A., Kunze, J. (1997) Foraging dynamics of bumblebees: correlates of movements within and between plant species. Behav. Ecol. 8(3), 239-249

Courtney, S.P., Hill, C.J., Westerman, A. (1982) Pollen carried for long periods by butterflies. Oikos 38(2), 260-263

Couvet, D. (2002) Deleterious effects of restricted gene flow in fragmented populations. Conserv. Biol. 16(2), 369-376

Darwin, C.R. (1886) Über die Wege der Hummelmännchen. In: Krause, E. (ed.) Gesammelte kleinere Schriften von Charles Darwin, 2nd edn, pp. 84-88. Germany, Leipzig

Dukas, R. (2001) Effects of predation risk on pollinators and plants. In: Chittka, L., Thomson, J.D. (eds.) Cognitive Ecology of Pollination-Animal Behaviour and Floral Evolution, pp. 214-236. Cambridge University Press, Cambridge

Durrer, S., Schmid-Hempel, P. (1994) Shared use of flowers lead to horizontal pathogen transmission. Proc. R. Soc. Lond. B 258, 299-302

Duvoisin, N., Baer, B., Schmid-Hempel, P. (1999) Sperm transfer and male competition in a bumblebee. Anim. Behav. 58, 743-749

Eickwort, G.C., Ginsberg, H.S. (1980) Foraging and mating behaviour in Apoidea. Annu. Rev. Entomol. 25, 421-446

Free, J.B., Williams, I.H. (1972) The transport of pollen on the body hairs of honeybees (Apis mellifera $\mathrm{L}$.) and bumblebees (Bombus spp. L.). J. Appl. Ecol. 9(2), 609-615

Garibaldi, L.A., Steffan-Dewenter, I., Winfree, R., Aizen, M.A., Bommarco, R., et al. (2013) Wild pollinators enhance fruit set of crops regardless of honeybee abundance. Science 339, 1608-1611

Gegear, R.J., Laverty, T.M. (2005) Flower constancy in bumblebees: a test of the trait variability hypothesis. Anim. Behav. 69, 939-949

GENSTAT for Windows 14th Edition. VSN International, Hemel Hempstead, UK. Web page: genstat.co.uk. 
Ghazoul, J. (2005) Pollen and seed dispersal among dispersed plants. Biol. Rev. 80, 413-443

Gögler, J., Stökl, J., Sramkova, A., Twele, R., Francke, W., Cozzolino, S., Cortis, P., Scrugli, A., Ayasse, M. (2009) Menage à Trois - two endemic species of deceptive orchids and one pollinator species. Evolution 63(9), 2222-2234

Goulson, D. (2003) Bumblebees-Behaviour and Ecology. United Kingdom, Oxford University Press, Oxford

Goulson, D., Hawson, S.A., Stout, J.C. (1997) Foraging bumblebees avoid flowers already visited by conspecifics or by other bumblebee species. Anim. Behav. 55, 199-206

Haas, A. (1949) Arttypische Flugbahnen von Hummelmännchen. Z. Vergl. Physiol. 31, 381-387

Hagbery, J., Nieh, J.C. (2012) Individual lifetime pollen and nectar foraging preferences in bumblebees. Naturwissenschaften 99, 821-832

Harder, L.D. (1985) Morphology as a predictor of flower choice by bumblebees. Ecology 66(1), 198-210

Heinrich, B. (1976) The foraging specializations of individual bumblebees. Ecol. Monogr. 46, 105-128

Heinrich, B. (1979a) "Majoring" and "minoring" by foraging bumblebees, Bombus vagans: an experimental analysis. Ecology 60(2), 245-255

Heinrich, B. (1979b) Bumblebee Economics. Harvard Univ. Press, Cambridge

Herrera, C.M. (1987) Components of pollinator "quality": comparative analysis of a diverse insect assemblage. Oikos 50, 79-90

Inouye, D.W. (1980) The effect of proboscis and corolla tube length son patterns and rates of flower visitation by bumblebees. Oecologia 45, 197-201

Kevan, P.G., Baker, H.G. (1983) Insects as flower visitors and pollinators. Ann. Rev. Entomol. 28, 407-453

Klein, A.M., Steffan-Dewenter, I., Tschantke, T. (2003) Fruit set of highland coffee increases with the diversity of pollinating bees. Proc. R. Soc. Lond. B 270, 955-961

Kraus, F.B., Wolf, S., Moritz, R.F.A. (2009) Male flight distance and population substructure in the bumblebee Bombus terrestris. J. Anim. Ecol. 78, 247-252

Kwak, M.M., Velterop, O., Andel, J. (1998) Pollen and gene flow in fragmented habitats. Appl. Veg. Sci. 1, 37-54

Laloi, D., Sandoz, J.C., Picard-Nizou, A.L., Marchesi, A., Pouvreau, A., Taséi, J.N., Poppy, G., PhamDelègue, M.H. (1999) Olfactory conditioning of the proboscis extension in bumblebees. Entomol. Exp. Appl. 90, 123-129

Lihoreau, M., Chittka, L., Raine, N.E., Kudo, G. (2011) Trade-off between travel distance and prioritization of high-reward sites in traplining bumblebees. Funct. Ecol. 25(6), 1284-1292

Lihoreau, M., Raine, N.E., Reynolds, A.M., Stelzer, R.J., Lim, K.S., Smith, A.D., Osborne, J.L., Chittka, L. (2012) Radar tracking and motion-sensitive cameras on flowers reveal the development of pollinator multi-destination routes over large spatial scales. PLoS Biol. 10(9), e1001392

Mauss V. (1994) Bestimmungsschlüssel für Hummeln. Hamburg, Germany. Deutscher Jugendbund für Naturbeobachtungen (DJN)

Menzel, R. (2001) Behavioural and neural mechanisms of learning and memory as determinants of flower constancy. In: Chittka, L., Thomson, J.D. (eds.) Cognitive Ecology of Pollination-Animal Behaviour and Floral Evolution, pp. 21-40. Cambridge University Press, Cambridge

Midgley, J.J., Bond, W.J. (1991) Ecological aspects of the rise of angiosperms: a challenge to the reproductive superiority hypotheses. Biol. J. Linn. Soc. 44, 81-92

Moeller, D.A. (2005) Pollinator community structure and sources of spatial variation in plant-pollinator interactions in Clarkia xantiana spp. xantiana. Oecologia 142, 28-37

Nilsson, L.A., Johnsson, L., Ralison, L., Randrianjohany, E. (1987) Angraecoid Orchids and Hawkmoths in Central Madagascar: Specialized Pollination Systems and Generalist Foragers. Biotropica 19(4), 310-318

Osborne, J.L., Martin, A.P., Carreck, N.L., Swain, J.L., Knight, M.E., Goulson, D., Hale, R.J., Sanderson, R.A. (2008) Bumblebee flight distances in relation to the forage landscape. J. Anim. Ecol. 77, 406-415

Ostervik, K.L., Manson, J.S., Thomson, J.D. (2010) Pollination potential of male bumblebees (Bombus impatiens): Movement patterns and pollen transfer efficiency. J. Poll. Ecol. 2(4), 21-26

Pyke, G.H. (1978) Optimal foraging: movement patterns of bumblebees between inflorescences. Theor. Popul. Biol. 13, 72-98

Raine, N.E., Chittka, L. (2005) Comparison of flower constancy and foraging performance in three bumblebee species (Hymenoptera: Apidae: Bombus). Entomol. Gen. 28(2), 81-89

Raine, N.E., Chittka, L. (2007) Flower constancy and memory dynamics in bumblebees (Hymenoptera: Apidae: Bombus). Entomol. Gen. 29(2/4), 179-199

Raine, N.E., Chittka, L. (2008) The correlation of learning speed and natural foraging success in bumblebees. Proc. R. Soc. Lond. B 275, 803-808

Ranta, E., Lundberg, H. (1981) Resource utilization by bumblebee queens, workers and males in a subarctic area. Hol. Ecol. 4, 145-154

Real, L.A. (1991) Animal choice behaviour and the evolution of cognitive architecture. Science 253(5023), 980-986

Sargent, R.D., Ackerly, D.D. (2008) Plant-pollinator interactions and the assembly of plant communities. Trends Ecol. Evol. 23(3), 123-130

Sork, V.L., Nason, J., Campbell, D.R., Fernandez, J.F. (1999) Landscape approaches to historical and contemporary gene flow in plants. Trends Ecol. Evol. 14(6), 219-224 
Spaethe, J., Weidenmüller, A. (2002) Size variation and foraging rate in bumblebees (Bombus terrestris). Insectes Soc. 49(2), 142-146

Svensson, B.G. (1979) Patrolling behaviour of bumblebee males (Hymenoptera: Apidae) in a Subalpine/ Alpine Area, Swedish Lapland. Zoon. 7, 67-94

Thomson, J.D. (1986) Pollen transport and deposition by bumblebees in Erythronium: Influences of floral nectar and bee grooming. J. Ecol. 74(2), 29-341

Thomson, J.D., Plowright, R.C. (1980) Pollen carryover, nectar rewards, and pollinator behavior with special reference to Diervilla lonicera. Oecologia 46, 68-74

Thorp, R.W. (1979) Structural, behavioural and physiological adaptations of bees (Apoidea) for collecting pollen. Ann. Missouri Bot. Gard. 66(4), 788-812

Von der Ohe, K., von der Ohe, W. (2003) Celle's Melissiopalynological collection, 2nd edn. Niedersächsisches Landesinstitut für Bienenkunde Celle, Celle

Waddington, K.D. (2001) Subjective evaluation and choice behaviour by nectar- and pollen collecting bees. In: Chittka, L., Thomson, J.D. (eds.) Cognitive Ecology of Pollination-Animal Behaviour and
Floral Evolution, pp. 41-60. Cambridge University Press, Cambridge

Waser, N.M. (1986) Flower constancy: definition, cause and measurement. Am. Nat. 27(5), 593-603

Weiss, M.R. (2001) Vision and learning in beetles, flies, moth and butterflies. In: Chittka, L., Thomson, J.D. (eds.) Cognitive Ecology of Pollination-Animal Behaviour and Floral Evolution, pp. 171-190. Cambridge University Press, Cambridge

Westerkamp, C. (1991) Honeybees are poor pollinators - why? Plant Syst Evol. 177, 71-75

Wolf, S., Moritz, R.F.A. (2008) Foraging distance in Bombus terrestris L. (Hymenoptera: Apidae). Apidologie 39, 419-427

Wolf, S., Toev, T., Moritz, R.V., Moritz, R.F.A. (2012) Spatial and temporal dynamics of the male effective population size in bumblebees (Hymenoptera: Apidae). Popul. Ecol. 54(1), 115-124

Wolfe, L.M., Barrett, S.C.H. (1989) Patterns of pollen removal and deposition in tristylous Pontederia cordata (Pontederiaceae). Biol. J. Linn. Soc. 36, 317-329 